\title{
Mechanical Analysis on Asphalt Mixture Overlaying on Old Cement Pavement Disengaged in the Corner
}

\author{
Yuqing Yuan ${ }^{1, a}$, Haitao Wan ${ }^{1, b}$, Sen Wen ${ }^{1, c}$, Wanli Zhan ${ }^{1, d}$ \\ ${ }^{1}$ School of Civil Engineering and Architecture, Henan University, Kaifeng 475004, Henan, China

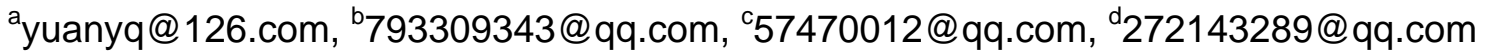

\begin{abstract}
Keywords: road engineering, old cement concrete pavement, disengaging, asphalt mixture overlaying, finite element method
\end{abstract}

\begin{abstract}
Based on the theory of elastic layer system, calculation models of asphalt overlaying on old cement pavement structure were established. According to finite element software, in allusion to a hollow under a slab's edge or its corner, series of key factors to stress and deflection of asphalt overlay have been studied, which includes cooling rate, axle load, and cement concrete slab thickness. In light of the calculation results, the development rules of stress and displacement were summarized. The relations between asphalt overlay equivalent stress, maximum shear stress, deflection and the influence factors were obtained, respectively.
\end{abstract}

\section{Introduction}

It's a very typical reconstruction method to use the asphalt concrete (AC) surface layer as the overlay on old cement concrete pavement (PCC). This kind of composite pavement structure can integrate two characteristics of asphalt and concrete, so it has the advantage of cliffside flower. Kong Ming analyzed the slab void impact on panel bearing capacity and the service life[1]. Miao calculated the stress of asphalt overlay changing with the void beneath the PCC under vehicle loads[2]. Li found that the shape of void beneath middle edge of PCC is close to rectangle or trapezium[3]. With finite element software, Xue analyzed dynamic load impact on void of PCC[4]. Wang discussed on the void in the edge and corner by ANSYS finite element software[5]. Tian et al researched on the effect of void on joint transfer ability of PCC[6]. With the software ABAQUS, Wang explored the stress of asphalt overlay impacted by void area, single slab void, double slabs void and load transfer ability[7]. The paper will build model and study on void impact on asphalt overlay on old cement concrete pavement. The paper will build model and study on void impact on asphalt overlay on old cement concrete pavement.

\section{Calculation model and parameters}

Calculation model. Domestic and foreign research shows that mechanics analysis of cement concrete pavement slab disengaged can be conducted accurately[8,9]. According to Chinese current cement concrete pavement design for highway (JTG D40-2011), a finite element method to finite size board on elastic foundation can be used for mechanical calculation. Therefore, large finite element analysis software ANSYS will be chosen to calculate cement concrete pavement slab disengaged mechanics calculation.

From the cause analysis trend of pavement disengaged, it can be seen that void mostly occurs first in the edge or angle of pavement slab. The results show that pavement void on a longitudinal edge has small impact to plate load stress, which can be not taken into account when mechanical analysis. There are different mechanics calculations between transverse edge and corner void of pavement slab, so different models should be built, respectively. Based on pavement slab bottom disengaging pattern of domestic and foreign studies, the models will be established as follows:

As for an asphalt overlaying on old cement concrete pavement with corner void structure, the corner is as the angular point, expanding into it with square shape in the horizontal direction.

Meanwhile, the pavement overlay structure is regarded as elastic layered system, consisting of asphalt overlay, stress absorbing layer, old cement concrete pavement, base and foundation from top to bottom, with which three dimensional model can be established. In order to reflect the 
semi-infinite space foundation characteristics, the foundation is simulated by the expanding size. An 8-node solid unit was used for asphalt overlay, stress absorbing layer, pavement, base and foundation. Moreover, as for the structure layer, some assumptions were made as following:

Each structured layers is uniform, continuous, isotropic elastic body. Each vertical, horizontal displacement between layers is continuous. Every direction displacement on the bottom and horizontal displacement on the side of foundation is zero. The pavement structure's weight influences will not be taken into account.

Parameters calculating. The size of cement concrete road pavement is taken as its actual length of $\mathrm{L}=5 \mathrm{~m}$, width of $\mathrm{B}=4 \mathrm{~m}$. And the expanding foundation dimensions are $7 \mathrm{~m} \times 6 \mathrm{~m} \times 6 \mathrm{~m}$. Main calculation parameters of each layer are displayed in Table 1.

Table 1 Main calculation parameters of each layer

\begin{tabular}{|c|c|c|c|c|c|}
\hline Structural layer & $\begin{array}{c}\text { Thickness } \\
(\mathrm{cm})\end{array}$ & $\begin{array}{c}\text { Elastic } \\
\text { modulus } \\
(\mathrm{MPa})\end{array}$ & $\begin{array}{c}\text { Poisson's } \\
\text { ratio } \\
/ \mathrm{u}\end{array}$ & $\begin{array}{c}\text { Thermal } \\
\text { conductivity } \\
\left(\mathrm{w} / \mathrm{m}^{\circ} \mathrm{C}\right)\end{array}$ & $\begin{array}{c}\text { Coefficient of } \\
\text { linear expansion } \\
\left(1 /{ }^{\circ} \mathrm{C}\right)\end{array}$ \\
\hline Asphalt concrete overlay & $5-9$ & $1200-2000$ & 0.25 & 1.2 & $2.1 \times 10^{-5}$ \\
\hline Stress absorbing layer & 2 & 800 & 0.25 & 1.2 & $2.1 \times 10^{-5}$ \\
\hline $\begin{array}{c}\text { Old cement concrete road } \\
\text { slab }\end{array}$ & 30 & 30000 & 0.15 & 1.5 & $1.5 \times 10^{-5}$ \\
\hline The basic level & 20 & 1200 & 0.20 & 1.0 & $0.5 \times 10^{-5}$ \\
\hline Foundation & - & 300 & 0.40 & 1.0 & $0.5 \times 10^{-5}$ \\
\hline
\end{tabular}

BZZ-100 was used as a standard traffic axle load, with a tire pressure of $0.7 \mathrm{MPa}$, a load radius of $10.65 \mathrm{~cm}$, and the space between two wheels $32 \mathrm{~cm}$.In consideration of calculation accuracy and easily units divided, the single wheel load ranging was confirmed as $20 \mathrm{~cm} \times 20 \mathrm{~cm}$ after trials. Compared the different position loading computational analysis, it is found that a void corner is the most harmful when wheels load on it, which is shown in Fig.1.

In order to improve the calculation accuracy, we mesh refine and encrypt the road structure near the void regions, pavement structure and void partial mesh. Calculating the temperature stress according to the most unfavorable situation, namely that the layers of completely continuous.

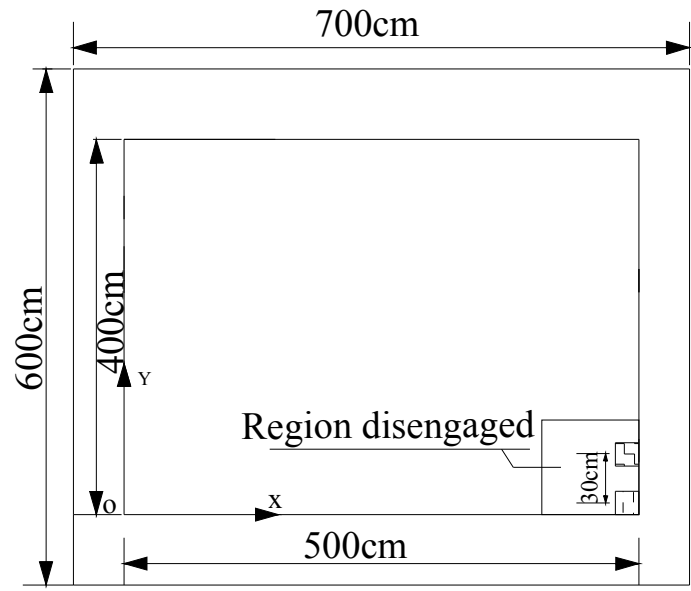

Fig. 1 Arrangement of calculating load

\section{Analysis of load and temperature}

Influences of cooling temperature range. The asphalt surface scopes are set as $5^{\circ} \mathrm{C}, 10^{\circ} \mathrm{C}, 15^{\circ} \mathrm{C}$, $20^{\circ} \mathrm{C}, 25^{\circ} \mathrm{C}$, which is coupled with the vehicle load BZZ-100. Then, computational analysis was put forward with the model. The other parameters are as fellows: thickness of asphalt layer $7 \mathrm{~cm}$, modulus $1600 \mathrm{MPa}$, and void thickness $10 \mathrm{~mm}$. The calculation results are as shown in Table 2 . 
Table 2 Results of cooling rate effect on stress and deflection of asphalt pavement

\begin{tabular}{|c|c|c|c|c|c|c|}
\hline $\begin{array}{c}\text { Temperature } \\
\text { changing }\left({ }^{\circ} \mathrm{C}\right)\end{array}$ & $\begin{array}{c}\sigma_{1} \\
(\mathrm{MPa})\end{array}$ & $\begin{array}{c}\sigma_{2} \\
(\mathrm{MPa})\end{array}$ & $\begin{array}{c}\sigma_{3} \\
(\mathrm{MPa})\end{array}$ & $\begin{array}{c}\sigma_{\mathrm{e}} \\
(\mathrm{MPa})\end{array}$ & $\begin{array}{c}\tau_{\max } \\
(\mathrm{MPa})\end{array}$ & $\begin{array}{c}\mu_{\mathrm{z}} \\
(0.01 \mathrm{~mm})\end{array}$ \\
\hline-5 & 0.30 & -0.13 & -0.89 & 0.94 & 0.60 & 56.6 \\
\hline-10 & 0.52 & -0.15 & -0.85 & 1.01 & 0.69 & 57.4 \\
\hline-15 & 0.74 & -0.17 & -0.81 & 1.08 & 0.78 & 58.2 \\
\hline-20 & 0.95 & -0.19 & -0.78 & 1.16 & 0.87 & 58.9 \\
\hline-25 & 1.17 & -0.21 & -0.75 & 1.23 & 0.96 & 59.7 \\
\hline
\end{tabular}

Known from Table 2, when the axle load of vehicle is fixed, the special three mechanics indexes of asphalt overlay, including equivalent stress $\sigma_{\mathrm{e}}$, maximum shear stress $\tau_{\max }$ and deflection $\mu_{\mathrm{z}}$ will tend an increasing trend with the slope of cooling, respectively. Each of the special three mechanics indexes increases $30.8 \%, 60.0 \%$ and $5.5 \%$, respectively, when the temperature drop value from $5{ }^{\circ} \mathrm{C}$ to $25{ }^{\circ} \mathrm{C}$. On basis of the results, it is implied that stress and deflection are significantly increased with the rate of temperature cooling.

As for old cement concrete pavement disengaged beneath the corner, when the other conditions are fixed, the formula about the relations between asphalt overlay's stress, deflection and cooling rate are as fellows equations:

$$
\left\{\begin{array}{l}
\sigma_{e}=3 e^{-5} T^{2}-0.0137 T+0.87 \\
\tau_{\max }=-0.018 T+0.51 \\
\mu_{z}=-0.0003 T^{2}-0.1626 T+55.8
\end{array}\right.
$$

Influences of axle load. To study influence of vehicle loads on the mechanics behaviour of asphalt overlaying old cement pavement structure with slab disengaged beneath the corner, a series of axle loads, including $100,120,140,160,180,200 \mathrm{kN}$, respectively, were coupled with $15^{\circ} \mathrm{C}$ cooling rate in the asphalt pavement surface. Then, the calculations were put forward with the model slab disengaged, a size of $100 \mathrm{~cm} \times 200 \mathrm{~cm} \times 10 \mathrm{~mm}$, beneath the corner. And the other calculation parameters were included, an asphalt pavement thickness of $7 \mathrm{~cm}$, with a module of $1600 \mathrm{MPa}$. The results are shown in Table 3.

Table 3 Results of axle load effect on stress and deflection of asphalt pavement

\begin{tabular}{|c|c|c|c|c|c|c|}
\hline Axle load $(\mathrm{kN})$ & $\begin{array}{c}\sigma_{1} \\
(\mathrm{MPa})\end{array}$ & $\begin{array}{c}\sigma_{2} \\
(\mathrm{MPa})\end{array}$ & $\begin{array}{c}\sigma_{3} \\
(\mathrm{MPa})\end{array}$ & $\begin{array}{c}\sigma_{\mathrm{e}} \\
(\mathrm{MPa})\end{array}$ & $\begin{array}{c}\tau_{\max } \\
(\mathrm{MPa})\end{array}$ & $\begin{array}{c}\mu_{\mathrm{z}} \\
(0.01 \mathrm{~mm})\end{array}$ \\
\hline 100 & 0.74 & -0.17 & -0.81 & 1.08 & 0.78 & 58.2 \\
\hline 120 & 0.76 & -0.20 & -1.00 & 1.26 & 0.88 & 69.3 \\
\hline 140 & 0.77 & -0.22 & -1.18 & 1.43 & 0.98 & 80.5 \\
\hline 160 & 0.79 & -0.24 & -1.36 & 1.60 & 1.08 & 91.6 \\
\hline 180 & 0.81 & -0.26 & -1.55 & 1.77 & 1.18 & 102.8 \\
\hline 200 & 0.83 & -0.29 & -1.73 & 1.95 & 1.28 & 114.0 \\
\hline
\end{tabular}

Based on the results, equivalent stress $\sigma_{\mathrm{e}}$, maximum shear stress $\tau_{\max }$, and deflection $\mu_{\mathrm{z}}$ increase by vehicle axle loads as cooling rate fixed, which can be learned from Table 3 . When the vehicle axle load increases from 100 to $200 \mathrm{kN}, \sigma_{\mathrm{e}}, \tau_{\max }$, and $\mu_{\mathrm{z}}$ respectively increase $80.6 \%, 64.1 \%$, and 95.9\%.

As for old cement concrete pavement disengaged beneath the corner, when the other conditions are fixed, the formula about the relations between asphalt overlay's stress, deflection and vehicle axle load are as fellows equations:

$$
\left\{\begin{array}{l}
\sigma_{e}=0.0086 P+0.2186 \\
\tau_{\max }=-9 e^{-19} P^{2}+0.005 P+0.28 \\
\mu_{z}=2 e^{-5} P^{2}+0.5513 P+2.8429
\end{array}\right.
$$




\section{Conclusions}

Along with cooling scope increasing, the stress and deflection of asphalt overlaying increase, but deflection addition is smaller. Stress and deformation have rapid increase under heavy transportation. When the vehicle axle load increases from 100 to $200 \mathrm{kN}, \sigma_{\mathrm{e}}, \tau_{\max }$, and $\mu_{\mathrm{z}}$ respectively increase $80.6 \%, 64.1 \%$, and $95.9 \%$. As for void beneath the corner, the thickness of old cement pavement has little impact on stress and deflection of asphalt overlaying.

\section{Acknowledgement}

The financial support of the National western traffic scientific \& technological program of China (No.200531881213), science \& technology project of Henan transport department (No.2010PII10), and Education Department of Henan Province Natural Science Research Project (No.2011A580001) are gratefully acknowledged. The authors would like to thank Prof. X.C. Wang for his valuable and helpful comments.

\section{References}

[1] M.Kong.Ultimate Bearing Capacity Analysis and Research of Portland Cement Concrete Pavement Structures.Changsha: Hunan University, 2006.

[2] L. Miao, C.Y. Zhang: Forest Engineering, Vol.13 (2007), p. 53-54.

[3] Y.Li.Research Of Void Evaluation Techniques Of Beneath Cement Pavement Based On Finite Element Analysis.Harbin: Northeast Forestry University, 2008.

[4] Z.J. Xue, J.N.Wang, X.N. Zhang and Y.Q.Tan: Journal of Harbin Institute of Technology, Vol. 41 (2009), p. 37-41.

[5] F.Wang.Research on Determination Method and Treatment Technology for VOids Beneath Cement Concrete Pavement.Xi'an: Chang'an University, 2009.

[6] X.G.Tian,F. YAO, S.Q.Zhang: Highway Engineering, Vol. 35 (2010), p. 24-27.

[7] W. Wang, J.L.Gao: Journal of China \& Foreign Highway, Vol. 32 (2012), p. 74-77.

[8] C.S.Guan: Journal of Wuhan University of technology,Vol. 28 (2006), p. 80-82.

[9] Q.Xie,Z.Y.He,L. Liang:Journal of Chongqing University,Vol. 31 (2008), p.726-728. 